\title{
PENERAPAN METODE VALUE ENGINEERING DALAM PEMILIHAN JENIS BETON PADA PROYEK KONSTRUKSI PERUMAHAN
}

\author{
Juan Aditya Kencana ${ }^{1}$ dan Mega Waty ${ }^{2}$ \\ ${ }^{1}$ Program Studi Sarjana Teknik Sipil, Universitas Tarumanagara, Jl. Letjen S. Parman No.1 Jakarta \\ juan.325170107@stu.untar.ac.id \\ ${ }^{2}$ Program Studi Sarjana Teknik Sipil, Universitas Tarumanagara, J1. Letjen S.Parman No.1 Jakarta \\ mega@ft.ac.id
}

\begin{abstract}
Value engineering is a technique to provide the necessary functions of a component or product at the lowest cost while meeting the specifications of quality, performance, and reliability. Development in the housing construction sector must be carried out as efficiently as possible by considering various factors. One of the most affecting factors is the selection of concrete types. The research was conducted on one of the housing projects located in Bumi Serpong Damai to know the most important criteria and the best alternative in selecting concrete types for housing projects. The criteria used are price, time, quality, ease of implementation, availability of tools and materials, technology, and concrete bearing capacity. Simultaneously, the alternatives reviewed are conventional concrete, ready mix concrete, and precast concrete. Research data in the form of questionnaires with the Saaty scale is analyzed by value engineering method with the Expert Choice program's help. Based on the analysis results, the most important criteria in selecting concrete types for residential projects are the quality of concrete with an eigen vector value of $31.1 \%$ and the best alternative was precast concrete with an eigen vector value of $47.8 \%$.
\end{abstract}

Keywords: value engineering; housing construction; concrete; criteria; alternative

\begin{abstract}
ABSTRAK
Value engineering adalah suatu teknik untuk memberikan fungsi yang diperlukan dari suatu komponen atau produk dengan biaya terendah sekaligus memenuhi spesifikasi kualitas, kinerja, dan keandalan. Pembangunan dibidang konstruksi perumahan dituntut untuk dilaksanakan seefisien mungkin dengan mempertimbangkan berbagai faktor yang ada. Salah satu faktor yang paling mempengaruhi yaitu pemilihan jenis beton. Penelitian dilakukan pada salah satu proyek perumahan yang terletak di Bumi Serpong Damai dengan tujuan mengetahui kriteria terpenting dan alternatif terbaik dalam pemilihan jenis beton untuk proyek perumahan. Kriteria yang digunakan adalah harga, waktu, kualitas, kemudahan pelaksanaan, ketersediaan alat dan material, teknologi, dan daya dukung beton, sedangkan alternatif yang ditinjau adalah beton konvensional, beton ready mix, dan beton pracetak / precast. Data penelitian berupa kuisioner dengan skala Saaty dianalisis dengan metode value engineering dengan bantuan program Expert Choice. Berdasarkan hasil analisis didapati kriteria terpenting dalam pemilihan jenis beton untuk proyek perumahan adalah kualitas beton dengan nilai eigen vector sebesar $31,1 \%$ dan alternatif terbaik berupa beton pracetak / precast dengan nilai eigen vector sebesar $47,8 \%$.
\end{abstract}

Kata kunci: value engineering; konstruksi perumahan; beton; kriteria; alternatif

\section{PENDAHULUAN}

Permasalahan dalam pembangunan konstruksi perumahan merupakan hal yang lumrah terjadi. Padahal, pembangunan dituntut untuk dilaksanakan seefisien mungkin dengan mempertimbangkan berbagai faktor yang ada.

Struktur bangunan merupakan hal terpenting yang perlu diperhatikan dalam konstruksi suatu bangunan. Hal ini disebabkan karena struktur bangunan berpengaruh besar terhadap kelayakan bangunan tersebut. Penggunaan material khususnya beton dalam pembangunan struktur bangunan perlu disesuaikan dengan kriteria-kriteria yang mendukung. Perencanaan material harus dilakukan dengan baik agar waste material yang dihasilkan tidak banyak, begitu pula dengan waktu dan biaya tidak mengalami pembengkakan (Amelia dan Sulistio, 2019). 
Salah satu metode analisis yang dapat digunakan dalam perencanaan material beton adalah value engineering atau rekayasa nilai. Dengan value engineering, maka dapat dilakukan perencanaan material yang sesuai kebutuhan sehingga akhirnya dapat menghasilkan pembangunan secara efisien.

Berdasarkan latar belakang yang ada, maka rumusan masalah pada penelitian ini adalah kriteria apa saja yang paling mempengaruhi pemilihan jenis beton dan jenis beton apakah yang terbaik untuk digunakan dalam konstruksi perumahan berdasarkan metode value engineering?

Tujuan penelitian ini adalah memperoleh kriteria yang paling dipertimbangkan dalam menentukan jenis beton dan mengetahui jenis beton terbaik yang dapat digunakan dalam proyek perumahan.berdasarkan metode value engineering.

\section{Value engineering}

Value engineering adalah evaluasi sistematis dari suatu proyek untuk mendapatkan nilai tertinggi untuk setiap biaya dengan cara menyelidiki biaya, ketersediaan bahan material, metode konstruksi, biaya pengiriman, perencanaan dan pengorganisasian, nilai atau manfaat, dan sejenisnya sehingga terjadi penurunan biaya proyek secara keseluruan (Fisk dan Reynold, 2010).

Menurut Edward Fisk (2010), fundamental dasar pada value engineering adalah function, worth, cost, dan value.

\section{a. Function}

Function (fungsi) didefinisikan untuk mencapai suatu tujuan spesifik atau digunakan untuk suatu penggunaan dalam hal ini menjelaskan apa yang akan dicapai.

b. Worth

Worth mengacu pada biaya paling sedikit yang diperlukan untuk menyediakan fungsi yang dibutuhkan oleh penggunanya yang berasal dari suatu proyek yang sudah selesai.

c. Cost

Cost (biaya) adalah jumlah uang yang dibutuhkan untuk mencapai suatu fungsi spesifik.

d. Value

Value (nilai) adalah hubungan antara harga dan biaya yang didasari oleh kebutuhan dan sumber daya dari pemiliknya.

\section{Analytical Hierarchy Process (AHP)}

Analytical Hierarchy Process (AHP) adalah sebuah alat pengambilan keputusan yang menggambarkan masalah kompleks dalam struktur hirarki dengan bermacam-macam derajat yang terdiri dari tujuan, kriteria dan alternatif. Pendekatan dasar untuk pengambilan keputusan dengan hierarki, masalah kompleks dan tidak terstruktur dipecah menjadi beberapa kelompok, kemudian diatur ke dalam hierarki (Sulistio et al., 2018).

Menurut Rais (2016), dalam menyelesaikan masalah menggunakan proses AHP, terdapat beberapa prinsip yang harus dipahami yaitu:

a. Membuat hierarki.

b. Penilaian kriteria dan alternatif.

c. Menentukan prioritas.

d. Konsistensi logis.

Expert Choice adalah sebuah software pengambil keputusan yang diimplementasikan pada Analytical Hierarchy Process (AHP). Dalam penggunaanya, program Expert Choice didasarkan pada pengidentifikasian masalah dengan menentukan Goal, Decision, dan Criteria.

\section{Beton}

Menurut Mehta (2006), komponen beton yaitu agregat, kerikil, pasir, mortar, semen, air, dan admixture.
a. Agregat
Agregat adalah bahan granular seperti pasir, kerikil, batu pecah yang disatukan dengan campuran semen untuk membentuk semen hidrolik.
b. Kerikil batu konglomerat yang terikat lemah.
c. Pasir
Kerikil adalah agregat kasar yang dihasilkan dari disintegrasi alami dan abrasi batuan atau pengolahan 
Pasir adalah agregat halus yang dihasilkan dari disintegrasi dan abrasi alami batuan atau dari pengolahan batu pasir.

d. Mortar

Mortar adalah hasil campuran dari air, semen, dan pasir. Pada dasarnya mortar merupakan beton namun tanpa agregat kasar dalam pembuatannya.

e. Semen

Semen adalah material berbentuk bubuk halus yang tidak memiliki sifat pengikat, tetapi dapat mengembangkan sifat pengikat jika tercampur dengan air.

f. Air

Penggunaan air dalam pembuatan beton harus memenuhi syarat sesuai dengan standar yang berlaku.

g. Admixture

Admixture adalah material selain air, agregat, atau semen hidrolis, yang digunakan sebagai bahan penyusun beton dan ditambahkan pada beton sebelum atau selama pencampurannya untuk memodifikasi properti.

\section{METODE PENELITIAN}

\section{Lokasi penelitian}

Penelitian dilakukan pada salah satu proyek konstruksi perumahan di Bumi Serpong Damai, Tangerang Selatan.

\section{Data penelitian}

Data-data yang diperlukan pada penelitian ini, yaitu:

a. Data primer

Data primer merupakan data pokok yang digunakan dalam melakukaan analisis value engineering. Dalam penelitian ini data primer diperoleh dari kuisioner. Kuisioner berisikan tentang perbandingan antar kriteria maupun alternatif yang ditinjau dengan menggunakan skala fundamental Saaty yang disajikan pada Tabel 1. Skala tersebut terdiri dari intensitas kepentingan 1 sampai 9 yang membandingkan tiap elemen yang ditinjau sesuai dengan tingkat kepentingannya.

Tabel 1. Skala fundamental Saaty

\begin{tabular}{cc}
\hline $\begin{array}{c}\text { Intensitas } \\
\text { kepentingan }\end{array}$ & Definisi \\
\hline 1 & Sama penting \\
3 & Elemen yang satu sedikit lebih penting dari elemen lainnya \\
5 & Elemen yang satu lebih penting daripada elemen lainnya \\
7 & Elemen yang satu sangat lebih penting daripada elemen lainnya \\
9 & Satu elemen mutlak penting dari pada elemen lainnya \\
$2,4,6,8$ & Nilai-nilai antara dua nilai pertimbangan yang berdekatan \\
Timbal- & Jika aktifitas i mendapat satu angka dibandingkan dengan aktifitas j, \\
balik & maka j memilki nilai kebalikannya dibandingkan dengan i \\
Rasio & Perbandingan yang timbul dari skala \\
\hline Sumber: Saty &
\end{tabular}

(Sumber: Saaty, 1987)

b. Data sekunder

Data sekunder merupakan data input yang dapat digunakan sebagai input dan referensi. Dalam hal ini data sekunder yang digunakan adalah rencana anggaran biaya, volume pengerjaan, daftar harga satuan pekerjaan, dan jenis-jenis beton yang digunakan sebagai alternatif-alternatif untuk bahan analisis.

\section{Pengolahan data}

Data yang diperoleh dilakukan analisis sesuai dengan tahapan kerja value engineering. Menurut Mandelbaum dan Reed (2006), tahapan kerja value engineering terbagi menjadi 8 tahap berdasarkan Department of Defense (DoD) yaitu tahap orinetasi, tahap informasi, tahap analisis fungsi, tahap kreatif, tahap evaluasi, tahap pengembangan, tahap presentasi, dan tahap implementasi. Namun dalam penelitian ini, tahap orientasi dan tahap implementasi tidak dapat dilakukan, sehingga tahapan yang digunakan adalah:

a. Tahap informasi 
Data-data seputar proyek yang diperlukan dalam penelitian akan dikumpulkan pada tahap informasi ini. Data-data tersebut merupakan data-data proyek yang akan dilakukan analisis dengan metode value engineering, dalam hal ini rencana anggaran biaya dari proyek. Selanjutnya dilakukan Hukum Distribusi Pareto untuk memilih pekerjaan yang dapat dikaji sesuai dengan batasan pada penelitian.

b. Tahap analisis fungsi

Dilakukan pendefinisian fungsi untuk pekerjaan beton yang akan dilakukan analisis, selanjutnya fungsi tersebut dijabarkan dalam bentuk Function Analysis System Technique (FAST) diagram agar pemilihan kriteria tidak terlepas dari fungsi yang akan diteliti.

c. Tahap kreatif

Pada tahap ini dilakukan identifikasi kriteria-kriteria yang akan diteliti. Kriteria-kriteria tersebut didapatkan dari penelitian-penelitian sebelumnya. Selain itu, kriteria-kriteria yang dipilih merupakan kriteria-kriteria yang paling dipertimbangkan oleh kontraktor dan pengembang pada konstruksi perumahan.

d. Tahap evaluasi

Pada tahap evaluasi diawali dengan analisis keuntungan maupun kerugian dari alternatif yang digunakan. Selanjutnya dilakukan pembuatan matriks perbandingan berpasangan untuk setiap data yang didapat dari responden.

e. Tahap pengembangan

Pada tahap pengembangan dilakukan perhitungan biaya untuk masing-masing alternatif yang diteliti. Selanjutnya dilakukan pengembangan terhadap matriks perbandingan berpasangan yang telah diperoleh sebelumnya dengan program Expert Choice untuk memperoleh kriteria maupun alternatif terbaik. Dalam pengembangan menggunakan Expert Choice, nilai inconsistency tiap responden pada matriks harus lebih kecil dari 0,1, jika lebih dari 0,1 maka perlu dilakukan perbaikan dengan cara improving inconsistency.

f. Tahap presentasi

Pada tahap ini, hasil dari penelitian berdasarkan analisis yang telah dilakukan akan dipaparkan secara jelas dan ringkas.

\section{HASIL DAN PEMBAHASANK}

\section{Tahap informasi}

Tabel 2. Cost model proyek

\begin{tabular}{|c|c|c|c|c|}
\hline No & Nama Pekerjaan & Biaya & Bobot $(\%)$ & $\begin{array}{c}\text { Bobot } \\
\text { Kumulatif (\%) }\end{array}$ \\
\hline 1 & Pekerjaan Struktur & Rp562.934.130 & 25,61 & 25,61 \\
\hline 2 & Pekerjaan Pelapis Dinding & Rp440.697.560 & 20,05 & 45,66 \\
\hline 3 & $\begin{array}{l}\text { Pekerjaan Kusen, Pintu, } \\
\text { Jendela }\end{array}$ & Rp259.600.000 & 11,81 & 57,48 \\
\hline 4 & Pekerjaan Lantai & Rp168.816.523 & 7,68 & 65,16 \\
\hline 5 & Pekerjaan Dinding & Rp163.361.240 & 7,43 & 72,59 \\
\hline 6 & Pekerjaan Instalasi Listrik & Rp123.943.315 & 5,64 & 78,23 \\
\hline 7 & Pekerjaan Fondasi & Rp96.507.450 & 4,39 & 82,62 \\
\hline 8 & Pekerjaan Plafond & Rp65.473.650 & 2,98 & 85,60 \\
\hline 9 & Pekerjaan Atap & Rp62.657.000 & 2,85 & 88,45 \\
\hline 10 & Pekerjaan Instalasi Air & Rp62.361.290 & 2,84 & 91,29 \\
\hline 11 & Pekerjaan Engsel dan Kunci & Rp59.617.788 & 2,71 & 94,00 \\
\hline 12 & Pekerjaan Sanitair & Rp52.490.568 & 2,39 & 96,39 \\
\hline 13 & Pekerjaan Pengecatan & Rp47.897.365 & 2,18 & 98,57 \\
\hline 14 & Pekerjaan Railling dan Tangga & Rp22.361.800 & 1,02 & 99,58 \\
\hline 15 & Pekerjaan Persiapan & Rp8.980.100 & 0,41 & 99,99 \\
\hline \multirow[t]{2}{*}{16} & Pekerjaan Lain-Lain & Rp164.000 & 0,01 & 100,00 \\
\hline & Total Biaya & Rp2.197.863.779 & 100,00 & \\
\hline
\end{tabular}


Pada tahap informasi, dimulai dengan dilakukan pengolahan data proyek berupa rancangan anggaran biaya. Data tersebut kemudian diurutkan berdasarkan besar bobot pekerjaan tersebut dari besar ke kecil atau yang dikenal dengan cost model proyek seperti yang disajikan pada Tabel 2. Cost model proyek kemudian dilakukan analisis dengan menggunakan Hukum Distribusi Pareto untuk mengetahui pekerjaan yang dapat dilakukan analisis dengan menggunakan metode value engineering. Diagram Pareto pada proyek disajikan dalam Gambar 1.

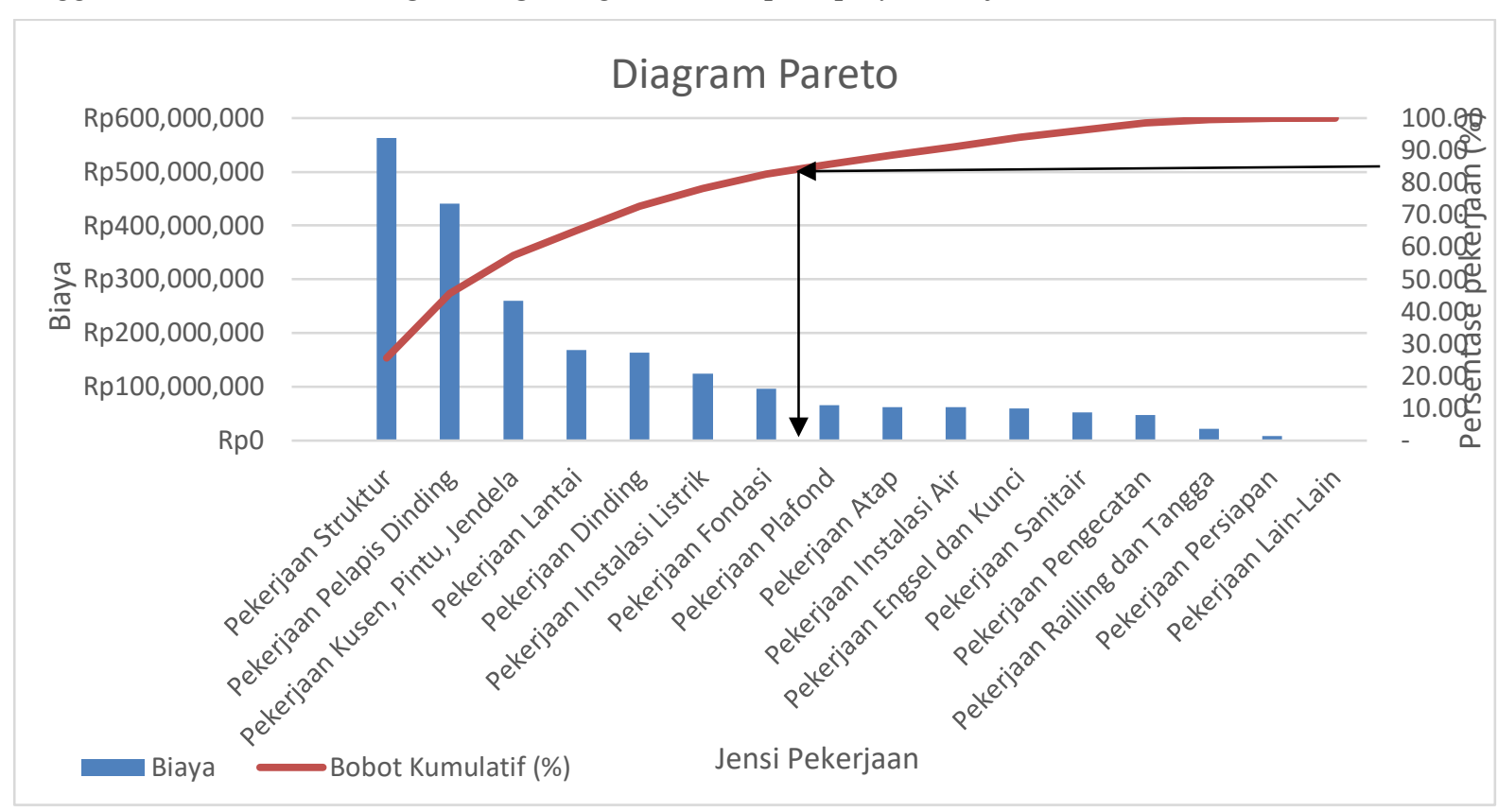

Gambar 1. Diagram Pareto

Diagram Pareto menyatakan bahwa $80 \%$ biaya total ditentukan oleh $20 \%$ kegiatan pekerjaan, maka sesuai dengan diagram di atas dapat disimpulkan pekerjaan yang paling strategis untuk dianalisis menggunakan metode value engineering adalah pekerjaan struktur, pekerjaan pelapis dinding, pekerjaan kusen, pintu, jendela, pekerjaan lantai, pekerjaan dinding, pekerjaan instalasi listrik, dan pekerjaan fondasi. Namun, untuk menyesuaikan dengan batasan pada penelitian ini, maka pekerjaan yang akan dilakukan analisis dengan metode value engineering adalah pekerjaan struktur dengan persentase tertinggi yang difokuskan pada pekerjaan beton dengan alternatif beton yang digunakan berupa beton konvensional, beton ready mix, dan beton pracetak.

\section{Tahap analisis fungsi}

Pada tahap analisis fungsi, dilakukan identifikasi fungsi-fungsi yang berhubungan dengan pekerjaan beton. Fungsi-fungsi tersebut terdiri dari kata kerja dan kata benda yang dikategorikan sesuai dengan tingkat kepentingan fungsi tersebut. Analisis fungsi beton disajikan pada Tabel 3.

Tabel 3. Analisis fungsi beton

\begin{tabular}{cccc}
\hline \multirow{2}{*}{ No } & \multicolumn{3}{c}{ Fungsi Beton } \\
\cline { 2 - 4 } & Kata Kerja & Kata Benda & Kategori \\
\hline 1 & Menyalurkan & Beban & Primer \\
2 & Menahan & Beban Tekan dan Tarik & Primer \\
3 & Membentuk & Struktur Bangunan & Primer \\
4 & Menjaga & Kestabilan Bangunan & Primer \\
5 & Memperkokoh & Bangunan & Primer \\
6 & Memberikan & Daya Dukung Bangunan & Primer \\
7 & Mengikat & Tulangan & Primer \\
8 & Menutup & Permukaan & Sekunder \\
9 & Memperpanjang & Umur Bangunan & Sekunder \\
10 & Menahan & Api & Sekunder \\
11 & Menahan & Cuaca & Sekunder \\
\hline
\end{tabular}


Fungsi-fungsi yang telah ditentukan kemudian dijabarkan dalam bentuk FAST diagram untuk mengetahui keterkaitan antara fungsi satu dengan fungsi lainnya sesuai dengan tingkat kepentingan fungsi tersebut. FAST diagram disajikan pada Gambar 2.

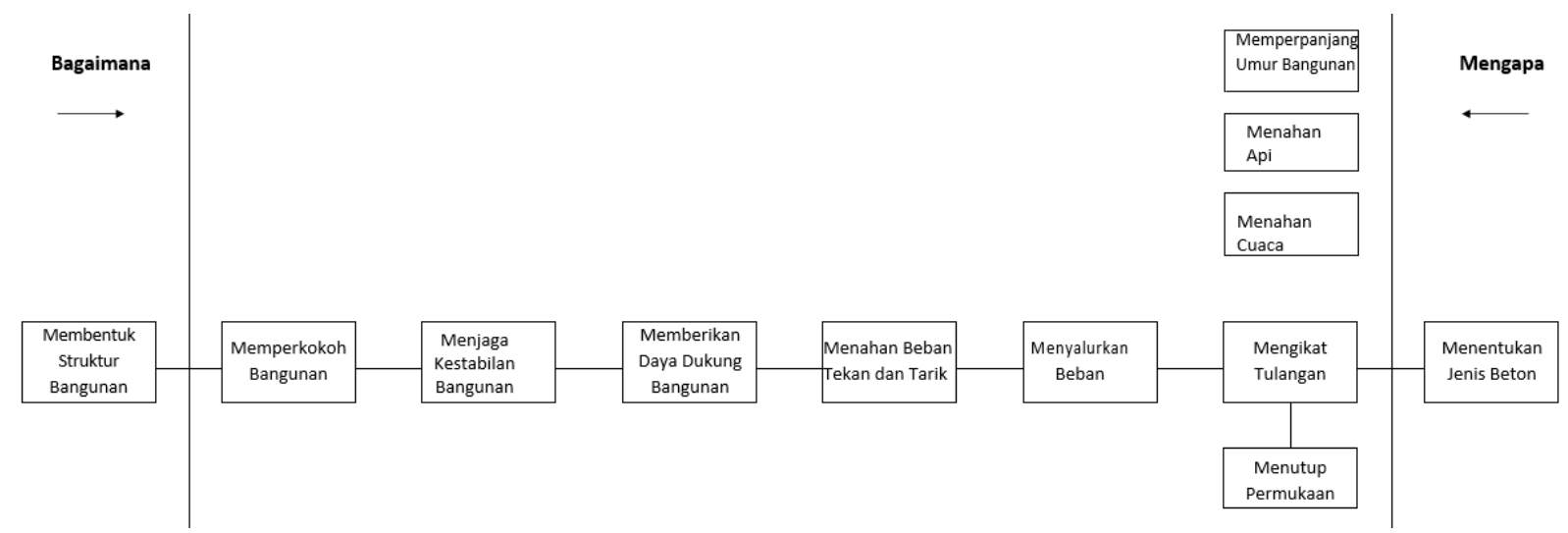

Gambar 2. FAST diagram beton

Berdasarkan Gambar 2, dapat dilihat fungsi dasar yang menjawab pertanyaan how yaitu membentuk struktur bangunan dan fungsi dasar yang menjawab pertanyaan why yaitu menentukan jenis beton. Fungsi-fungsi yang berada di antara kedua fungsi dasar tersebut pada alur horizontal merupakan jawaban dari fungsi sebelumnya. Selain alur horizontal, terdapat juga fungsi-fungsi yang berada pada alur vertikal, yaitu fungsi yang dilakukan secara bersamaan dengan fungsi di bawahnya.

\section{Tahap kreatif}

Pada tahap ini, dilakukan identifikasi kriteria-kriteria yang akan digunakan dalam analisis Kriteria-kriteria yang digunakan adalah sebagai berikut:
a. Harga atau biaya pengerjaan
b. Waktu pengerjaan
c. Kualitas
d. Kemudahan pelaksanaan
e. Ketersediaan alat dan material
f. Teknologi yang digunakan
g. Daya dukung beton

\section{Tahap evaluasi}

Tahap evaluasi diawali dengan melakukan analisis keuntungan dan kerugian untuk tiap alternatif yang diteliti. Analisis tersebut dapat dilihat pada Tabel 4, Tabel 5, dan Tabel 6.

Tabel 4. Analisis keuntungan dan kerugian beton konvensional

\begin{tabular}{ll}
\hline \multicolumn{1}{c}{ Keuntungan } & \multicolumn{1}{c}{ Kerugian } \\
\hline $\begin{array}{l}\text { Beton konvensional dapat dibuat pada tempat } \\
\text { yang relatif sempit. }\end{array}$ & $\begin{array}{l}\text { Waktu pengerjaan yang lama karena harus } \\
\text { menunggu selama 28 hari hingga beton } \\
\text { mendapat daya tahan maksimalnya. }\end{array}$ \\
$\begin{array}{l}\text { Pengawasan dalam pembuatan, penempatan, } \\
\text { dan peawatan beton konvensional lebih mudah }\end{array}$ & $\begin{array}{l}\text { Memerlukan banyak pekerja dalam } \\
\text { pembuatannya }\end{array}$ \\
$\begin{array}{l}\text { untuk dilakukan. } \\
\text { Tidak memerlukan biaya yang besar untuk } \\
\text { transportasi beton konvensional. }\end{array}$ & $\begin{array}{l}\text { Memerlukan pemakaian bekisting sehingga } \\
\text { Mudah dan umum dalam perhitungan maupun } \\
\text { pengerjaannya }\end{array}$ \\
\hline
\end{tabular}


Tabel 5. Analisis keuntungan dan kerugian beton ready mix

\begin{tabular}{|c|c|}
\hline Keuntungan & Kerugian \\
\hline Memiliki kualitas yang lebih baik & $\begin{array}{l}\text { Tidak dapat dilakukan pada tempat proyek yang } \\
\text { relatif kecil }\end{array}$ \\
\hline $\begin{array}{l}\text { Dapat melakukan penghematan pada biaya } \\
\text { penyimpanan material beton dan alat pembuat } \\
\text { beton }\end{array}$ & Membutuhkan biaya awal yang lebih besar \\
\hline $\begin{array}{l}\text { Kelebihan material yang terbuang dapat } \\
\text { dikurangi }\end{array}$ & $\begin{array}{l}\text { Membutuhkan transportasi yang efektif dari } \\
\text { pabrik pembuatan menuju ke tempat proyek }\end{array}$ \\
\hline Memerlukan pekerja yang sedikit & $\begin{array}{l}\text { Rentang waktu beton yang terbatas antara } \\
\text { pencampuran dan pelepasan. }\end{array}$ \\
\hline Waktu pengerjaan relatif lebih cepat & $\begin{array}{l}\text { Memerlukan pemakaian bekisting dalam } \\
\text { pembuatannya sehingga memerlukan biaya } \\
\text { khusus }\end{array}$ \\
\hline
\end{tabular}

Tabel 6. Analisis keuntungan dan kerugian beton pracetak

\begin{tabular}{ll}
\hline \multicolumn{1}{c}{ Keuntungan } & \multicolumn{1}{c}{ Kerugian } \\
\hline Memiliki kualitas yang lebih baik & $\begin{array}{l}\text { Memerlukan biaya yang besar di awal } \\
\text { pengerjaan }\end{array}$ \\
$\begin{array}{l}\text { Hanya memerlukan waktu pemasangan } \\
\text { sehingga waktu pengerjaan dapat dipercepat dapat dilakukan pada tempat proyek yang } \\
\text { Tidak } \\
\text { relatif kecil } \\
\text { penyimpanan material beton dan alat pembuat } \\
\text { beton }\end{array}$ & $\begin{array}{l}\text { Membutuhkan transportasi yang efektif dari } \\
\text { pabrik ke tempat proyek }\end{array}$ \\
$\begin{array}{l}\text { Tidak ada limbah sisa material karena } \\
\text { penggunaan sesuai dengan yang dibuthkan }\end{array}$ & $\begin{array}{l}\text { Karena dibuat di pabrik, memiliki bentuk dan } \\
\text { ukuran yang terbatas } \\
\text { Tidak memerlukan pekerja yang banyak }\end{array}$ \\
\hline
\end{tabular}

Selanjutnya, alternatif-alternatif beserta kriterianya akan diberikan pembobotan oleh responden dalam bentuk kuisioner yang disebarkan kepada pihak yang bekerja di bidang konstruksi antara lain konsultan, owner, kontraktor, dan sebagainya. Dari kuisioner yang disebarkan, didapat data dari 32 responden. Data tersebut kemudian diolah ke dalam matriks perbandingan berpasangan.

\section{Tahap pengembangan}

Pada tahap ini akan dilakukan perhitungan biaya untuk tiap alternatif yang digunakan. Perhitungan biaya tersebut didapat dari volume pekerjaan dikalikan dengan analisis harga satuan pekerjaan. Untuk beton pracetak, karena desain alternatif tidak tersedia, maka diasumikan menggunakan volume yang sama sesuai dengan desain yang ada. Biaya yang dihitung merupakan biaya material ditambah biaya tenaga kerja. Perhitungan disesuaikan dengan Pedoman Analisis Harga Satuan Pekerjaan Bidang Pekerjaan Umum tahun 2016. Dari perhitungan, didapatkan biaya untuk beton konvensional sebesar Rp122.243.604,00, beton ready mix sebesar Rp126.643.500,00, dan beton pracetak sebesar Rp147.116.889,00.

Selanjutnya untuk mendapatkan kriteria maupun alternatif terbaik, dilakukan pengembangan pada matriks perbandingan berpasangan yang telah diperoleh sebelumnya dengan bantuan program Expert Choice. Rata-rata matriks perbandingan berpasangan dari semua data responden dapat dilihat pada Gambar 3.

\begin{tabular}{|c|c|c|c|c|c|c|c|}
\hline & Harga & Waktu & Kualitas & Kemudahan Pelaksanaan & Ketersediaan Alat dan Material & Teknologi & Daya Dukung Beton \\
\hline Harga & & 1,77192 & 3,70698 & 1,81378 & 1,22104 & 1,77995 & 2,89595 \\
\hline Waktu & & & 2,45245 & 1,06968 & 1,70949 & 3,19372 & 2,10334 \\
\hline Kualitas & & & & 3,0745 & 3,63302 & 4,7093 & 1,56958 \\
\hline Kemudahan Pelaksanaan & & & & & 1,32669 & 2,42686 & 2,03476 \\
\hline Ketersediaan Alat dan Material & & & & & & 1,94858 & 2,37954 \\
\hline Teknologi & & & & & & & 3,99377 \\
\hline Daya Dukung Beton & Incon: 0,01 & & & & & & \\
\hline
\end{tabular}

Gambar 3. Rata-rata matriks perbandingan berpasangan 
Dari matriks tersebut, dengan metode Analytical Hierarchy Process (AHP) dengan bantuan program Expert Choice dicari nilai eigen vector untuk tiap kriteria maupun alternatif yang ditinjau. Nilai eigen vector untuk kriteria dan alternatif dapat dilihat pada Gambar 4 dan Gambar 5.
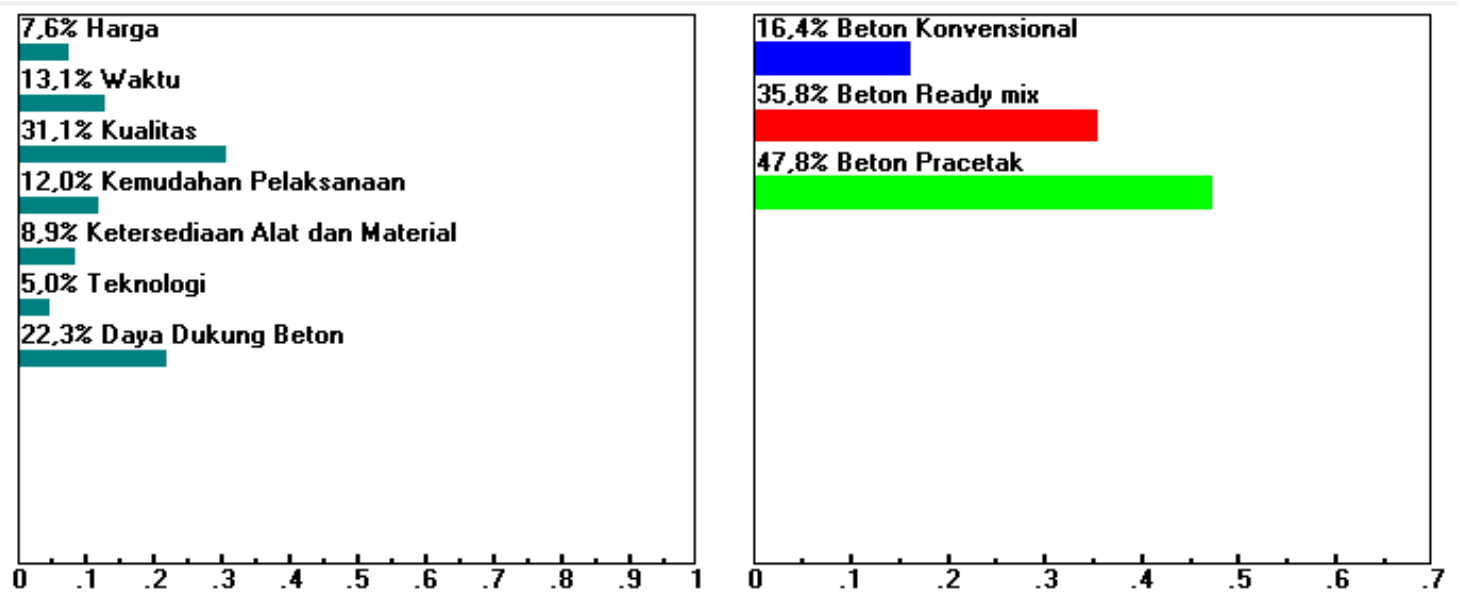

Gambar 4. Nilai eigen vector untuk kriteria dan alternatif

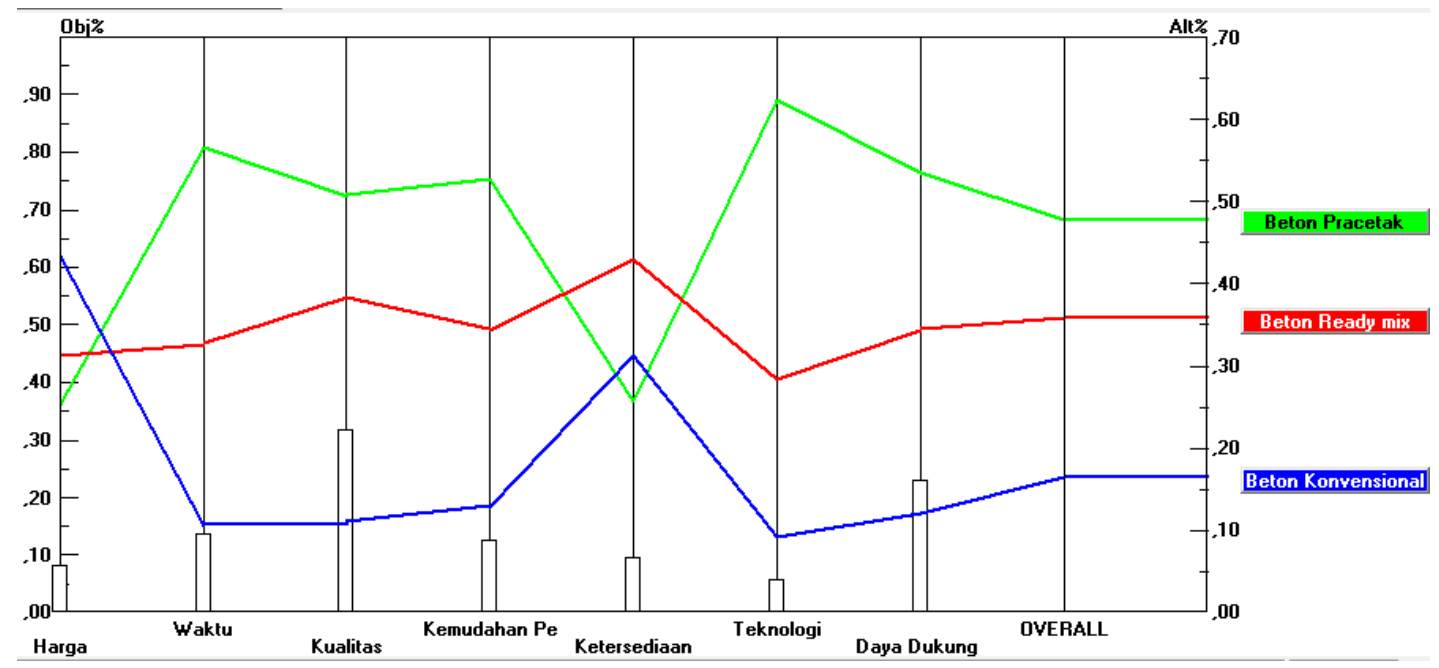

Gambar 5. Grafik performance sensitivity

Berdasarkan Gambar 5, nilai eigen vector untuk kriteria kepentingan ditunjukkan dalam bentuk grafik batang yaitu dengan kriteria terpenting berupa kualitas diikuti oleh daya dukung, waktu, kemudahaan pelaksanaan, ketersediaan alat dan material, harga, dan teknologi. Kemudian, nilai eigen vector untuk tiap alternatif ditunjukkan dalam bentuk grafik garis. Nilai eigen vector tersebut merupakan perbandingan antara tiap alternatif berdsarkan kriteriakriteria yang digunakan. Beton konvensional memiliki nilai eigen vector tertinggi pada kriteria harga, beton ready mix memiliki nilai eigen vector tertinggi pada kriteria ketersediaan alat dan material, dan beton pracetak memiliki nilai eigen vector tertinggi pada kriteria waktu, kualitas, kemudahan pelaksanaan, teknologi, dan daya dukung beton. Oleh karena itu, secara overall, alternatif terbaik adalah beton pracetak diikuti oleh beton ready mix dan terakhir beton konvensional.

\section{Tahap presentasi}

Berdasarkan analisis yang dilakukan, didapati bahwa alternatif yang paling disarankan dalam pengerjaan proyek perumahan merupakan beton pracetak / precast. Alasan pemilihan alternatif tersebut dibanding alternatif lainnya yaitu karena terdapat keunggulan pada kriteria-kriteria seperti waktu, kualitas, kemudahan pelaksanaan, dan teknologi walaupun terdapat juga kriteria-kriteria yang kurang diunggulkan seperti harga dan ketersediaan alat dan material. 


\section{KESIMPULAN DAN SARAN}

\section{Kesimpulan}

Berdasarkan analisis yang dilakukan, dapat diambil kesimpulan, yaitu:

1. Kriteria yang paling dipertimbangkan dalam menentukan jenis beton pada proyek perumahan berdasarkan metode value engineering yaitu kualitas beton dengan nilai pembobotan sebesar 0,311 atau $31,1 \%$, diikuti oleh kriteria daya dukung beton 0,223 atau $22,3 \%$, kriteria waktu 0,131 atau 13,1\%, kriteria kemudahan pelaksanaan 0,120 atau $12,0 \%$, kriteria ketersediaan alat dan material 0,089 atau $8,9 \%$, kriteria harga 0,076 atau $7,6 \%$, dan kriteria teknologi 0,05 atau $5 \%$.

2. Beton terbaik yang dapat digunakan dalam proyek perumahan adalah beton pracetak / precast dengan nilai pembobotan sebesar $47,8 \%$. Alternatif tersebut didukung dengan nilai pembobotan tertinggi pada kriteria kualitas, kriteria daya dukung, kriteria waktu, kriteria kemudahan pelaksanaan, dan kriteria teknologi sebesar $83,5 \%$ dari total $100 \%$. Walaupun untuk beton pracetak, kriteria harga dan ketersediaan alat dan material mendapatkan nilai pembobotan terendah, namun kedua kriteria tersebut hanya memiliki $16,5 \%$ dari total $100 \%$.

\section{Saran}

Berdasarkan kesimpulan yang didapat, dapat diberikan saran untuk kedepanya, yaitu:

1. Disarankan dalam pemilihan jenis beton yang digunakan di proyek perumahan untuk memberikan perhatian lebih kepada kriteria kualitas karena merupakan kriteria dengan nilai bobot tertinggi sesuai dengan analisis yang telah dilakukan.

2. Penelitian ini terbatas kepada pekerjaan beton dalam proyek perumahan. Untuk memperluas penelitian ini, maka pada penelitian-penelitian selanjutnya dapat dilakukan analisis pada item pekerjaan lainnya dalam proyek perumahan seperti pekerjaan atap, pekerjan ME, ataupun pekerjaan lainnya.

\section{DAFTAR PUSTAKA}

Amelia, Hanifah dan Hendrik Sulistio. "Analisis Value Engineering pada Proyek Perumahan Djajakusumah Residence." JMTS: Jurnal Mitra Teknik Sipil 2.3 (2019): 209-216.

Fisk, Edward and Wayne D. Reynolds. Construction Project Administration Ninth Edition. New Jersey: Pearson Education, Inc., 2010.

Mandelbaum, Jay and Danny L. Reed. Value Engineering Handbook. Virginia: Institute for Defense Analyses, 2006.

Mehta, P. Kumar and Paulo J. M. Monteiro. Concrete : Microstructures, Properties, and Materials. Berkeley: The McGraw-Hill Companies, Inc. , 2006.

Menteri Pekerjaan Umum dan Perumahan Rakyat Republik Indonesia. "Pedoman Analisis Harga Satuan Pekerjaan Bidang Pekerjaan Umum”. Jakarta: Kementerian PUPR, 2016.

Rais, Mhd. Sandi. "Sistem Pendukung Keputusan Untuk Pemilihan Lokasi Perumahan Menggunakan Analytical Hierarchy Process (AHP)." Riau Journal Of Computer Science 2.2 (2016): 59-72.

Saaty, R. W. "The Analytic Hierarchy Process-What It Is and How It Is Used." Mathematical modelling 9.3-5 (1987): 161-176.

Sulistio, Hendrik, et al. "Sensitivity Analysis with AHP Method: Selection of Foundation Design on Bridge Sei Muara Bulan Anak 2." JPhCS 1028.1 (2018): 012069. 
Penerapan Metode Value Engineering dalam Pemilihan Jenis

Juan Aditya Kencana, et al.

Beton pada Proyek Konstruksi Perumahan 